\title{
PADRONIZAÇÃO E APLICAÇÃO DA CURVA DE FRAGILIDADE OSMÓTICA NO AUXÍLIO DIAGNÓSTICO DE ANEMIAS
}

CAIRES, Ana Carla. Biomédica formada pelo Centro Universitário de Araraquara - Uniara.

GILENO, Miriane da Costa. Mestre e doutora em Análises Clínicas (FCF-Unesp), professora de Hematologia Clínica e Bioquímica e Enzimologia Clínica. Curso de Biomedicina. Laboratório de

Hematologia Clínica. Centro Universitário de Araraquara - Uniara. Tel: (16) 3331-5985.

E-mail: mcostagileno@yahoo.com.br.

\section{Resumo}

$\mathrm{Na}$ Curva de Fragilidade Osmótica as hemácias são submetidas a concentrações crescentes de cloreto de sódio e o percentual de hemólise é avaliado pela quantidade de hemoglobina livre em solução. Ocorre aumento da resistência globular na anemia ferropriva e talassemia, e diminuição da resistência na esferocitose hereditária e esferocitose associada às anemias hemolíticas autoimunes. Este trabalho objetivou padronizar essa curva com relação à necessidade e tempo de incubação, caracterizar curvas de pacientes anêmicos e testar sua eficiência em estudo cego, auxiliando na caracterização de anemias. Foram obtidos $4 \mathrm{~mL}$ de sangue total de sujeitos divididos em três grupos de pesquisa: 1) 15 indivíduos saudáveis;2) 15 indivíduos com hemograma apresentando microcitose, esferocitose, macrocitose, hemácia em alvo, hemácias falciformes, desvio à esquerda/granulações tóxicas; 3) 10 indivíduos com hemograma alterado (estudo cego). O sangue foi pipetado em tubos com solução de cloreto de sódio a $1 \%$ e água destilada. Após centrifugação, realizou-se a leitura dos sobrenadantes em 540 $\mathrm{nm}$. As curvas do grupo 1 foram realizadas sem e com incubação de 24 e 48 horas a $37^{\circ} \mathrm{C}$. Na padronização, não se observou diferença nas curvas com ausência e presença de incubação. Ficou evidente a curva no caso de macrocitose, microcitose e presença de hemoglobina $S$; não houve alterações na curva com desvio à esquerda, granulações tóxicas e eliptócitos. Constatou-se que não existe necessidade de incubação para execução do método e é útil quando associado ao hemograma para auxílio na caracterização de anemias megaloblásticas, anemia ferropriva, presença de $\mathrm{HbS}$ e talassemia.

Palavras-chave: Curva; Fragilidade osmótica; Eritrócitos.

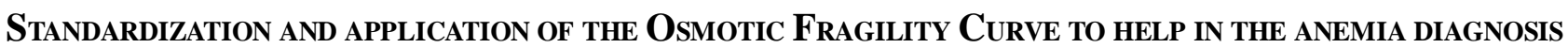

\section{Abstract}

At the Osmotic Fragility Curve the erythrocytes are submitted to crescent concentrations of sodium chloride, and the hemolysis percent is available by the quantity of free hemoglobin in solution. Increased resistance occurs in globular anemia and thalassemia, and decreased resistance, in hereditary spherocytosis associated with spherocytosis and hemolytic anemia. This research objective was to standardize the curve according to need and incubation time, to characterize curves of anemic patients and test its efficiency in a blind study, helping on anemia's characterization. Total blood was collected from individuals distributed in three different search groups: 1) 15 healthy individuals;2) 15 individuals with hemograms showing microcytosis, spherocytosis, macrocytosis, target erythrocytes, sickle erythrocytes, a left shift and toxic granulation;3) 10 individuals withaltered hemogram (blind study). The blood was pipetted in tubes with a solution of sodium chloride $1 \%$ and distilled water. After centrifugation, the reading of the supernatant at $540 \mathrm{~nm}$ was performed. The curves of group 1 were done with and without incubation of 24 and 48 hours at $37{ }^{\circ} \mathrm{C}$. In standardization, no difference was observed in the curves with the absence and presence of incubation. In the case of macrocytosis, microcytosis and presence of hemoglobin S, the curve was evident; there were no alterations in the curve with a left shift, toxicgranulation and 
elliptocytes. It was observed that there is no need for incubation execution. The method is useful when associated with hemogram to help in the characterization of megaloblastic anemia, iron deficiency anemia, presence of $\mathrm{HbS}$ and thalassemia.

KeYwords: Curve; Osmotic fragility; Erythrocytes.

\section{INTRODUÇÃo}

A Curva de Fragilidade Osmótica-CFO é também conhecida como: Curva de Resistência Globular; Prova de Resistência Osmótica; Prova de Fragilidade Osmótica; Curva de Hemólise; Resistência Osmótica das Hemácias. Já a anemia pode ser conceituada como a queda do conteúdo de hemoglobina, que pode coincidir ou não com a diminuição no número de eritrócitos. A curva avalia a capacidade dos glóbulos vermelhos de incorporar água em seu interior, semque ocorra a lise da célula. (CEACLIN, 2012) Por esse motivo se pode dizer que a resistência está na dependência da relação entre volume/superfície do glóbulo.

A CFO é um teste que pode ser usado no auxílio da caracterização de diversas anemias, que apresentam como característica principal a diferença de tamanho e forma das hemácias. No entanto, o teste é de difícil padronização, e por esse motivo pouco realizado nos laboratórios.

Pode-se observar que há um aumento da resistência globular na anemia ferropriva, assim como na talassemia, e há uma diminuição dessa resistência na esferocitose hereditária e esferocitose associada a anemias hemolíticas autoimunes. O volume recomendável para coleta é de 4,0 $\mathrm{ml}$ de sangue. O sangue coletado deverá ser conservado em até seis horas (temperatura ambiente) (PARDINI, 2012).

A curva se apresentará aumentada em: anemia esferocítica hereditária, anemia hemolítica nãoesferocítica hereditária, anemia hemolítica adquirida, doença hemolítica do recém-nascido, devido à incompatibilidade $\mathrm{ABO}$, alguns casos de anemia hemolítica secundária, após queimaduras graves, envenenamento químico e anemia hemolítica secundária, em alguns casos de linfoma maligno, leucemia, carcinoma, gestação, cirrose e infecção. A curva se apresentará diminuída em: início da infância, anemia ferropriva, talassemia, anemia falciforme, doença da hemoglobina C homozigótica, anemia megaloblástica nutricional, pós-esplenectomia, doença hepática e icterícia (WALLACH, 2003; PARDINI, 2012; KHURANA, 2006; WILIAMS e WILKINS, 2007; FISCHBACH e DUNNING, 2008).

Como são várias as patologias em que observamos alterações na curva de fragilidade osmótica, pontuamos aquelas anemias mais expressivas pelo seu significado clínico e social:

AAnemia Hemolítica Esferocítica Constitucional ou Esferocitose Hereditária-EH é um distúrbio causado pela alteração da membrana dos eritrócitos e possui transmissão autossômica dominante (VERRASTRO et al., 2002). É caracterizada por anemia leve, esplenomegalia e ocorre o aumento de esferócitos no sangue periférico, denominado esferocitose (LEE $e t$ al., 1998). Na EH, os eritrócitos possuem alterações que desencadeiam a diminuição da deformabilidade $\mathrm{e}$ predisposição ao aprisionamento esplênico (ZAGO et al., 2001), e o pré-requisito para hemólise é um baço normal (LEE et al., 1998).

Já a anemia megaloblástica é caracterizada por alterações morfológicas na medula óssea, que passa a produzir eritrócitos macrocíticos (ZAGO et al., 2001), e este tipo de anemia é resultante da carência de vitamina B12 (cobalamina) e/ou Folatos (ácido fólico). A carência de folatos ou vitamina B12 gera distúrbios na multiplicação celular envolvendo a síntese de DNA, pois a presença de folatos e vitamina B12 é essencial para a produção de timidina, um dos nucleotídeos que forma o DNA. Portanto, ocorrendo a carência de folatos e/ou vitamina B12 haverá uma menor síntese de DNA (ZAGO et al., 2001).

A anemia falciforme (doença SS) é uma hemoglobinopatia genética onde ocorre alteração na estrutura da molécula de hemoglobina (HbA1), denominada hemoglobina $\mathrm{S}(\mathrm{HbS})$, que provoca distorção da morfologia dos eritrócitos, passando de forma esférica para a forma de "foice" (sickle-cell), 
fenômeno de falcização, quando expostas à queda da tensão de oxigênio (BRASIL, 2006; ZAGO et al., 2001).

A anemia ferropriva é causada pela deficiência de ferro, que é utilizado na produção dos eritrócitos, e sua presença é essencial para a síntese de heme e, portanto, de hemoglobina. Cerca de $80 \%$ do ferro absorvido pelo trato gastrointestinal - TGI destina-se à hemoglobina (KELLEY, 1999). A deficiência de ferro pode causar uma anemia ferropriva, com diminuição nos valores da hemoglobina, causando, consequentemente, hipocromia e microcitose. A anemia microcítica hipocrômica compromete a liberação de oxigênio para os tecidos, provocando fraqueza, fadiga, palpitações e tonteira (KELLEY, 1999).

As síndromes talassêmicas são distúrbios hereditários da síntese das cadeias de globina $\alpha$ ou $\beta$. Podemos observar talassemias alfa, beta, delta-beta e gama-delta-beta. Os fenótipos das talassemias do tipo alfa e tipo beta são aqueles de importância em termos de saúde publica (POYART e WAJCMAN, 1996; WEATHERALL, 1997).

A primeira anormalidade bioquímica nas talassemias é resultante do defeito quantitativo na síntese de um determinado tipo de cadeia, o que leva ao decréscimo da hemoglobina eritrocitária (hipocromia), juntamente com a presença de um excesso de cadeias normalmente sintetizadas. Essas, não tendo possibilidade de encontrar seus pares, se tetramerizam entre si, sofrendo precipitação e ligação à membrana, provocando hemólise (SCHWARTZ, 1974; POYART e WAJCMAN, 1996).

Portanto, os objetivos do presente trabalho foram: primariamente padronizar a curva de fragilidade osmótica junto ao laboratório de Hematologia Clínica do Centro Universitário de Araraquara - Uniara. Depois, caracterizar as curvas nos casos de algumas alterações hematológicas, como anemia megaloblástica, anemia esferocítica e hemácias microcíticas, e depois realizar um estudo cego com hemogramas alterados e demonstrar a eficiência da curva de fragilidade osmótica na caracterização de algumas patologias.

\section{Material e Métodos}

(Protocolo n. ${ }^{\circ} 831$ - Aceito pelo Comitê de Ética) Apresentação e caracterização do universo da pesquisa

As coletas de sangue e as análises laboratoriais foram realizadas no Laboratório de Hematologia Clínica e Imunologia Clínica do Centro Universitário de Araraquara - Unidade II. O presente laboratório conta com infraestrutura apropriada para realização de coletas de sangue e para manuseio, estoque, incubação e descarte de amostras biológicas.

Delimitação e caracterização dos sujeitos/ indivíduos da pesquisa e da amostragem da pesquisa

Padronização da Curva de Fragilidade Osmótica (primeira etapa): foram obtidos $4 \mathrm{~mL}$ de sangue total colhidos por punção venosa, em tubo com $\mathrm{K}_{2}$-EDTA, utilizando seringa e agulha descartáveis. A coleta, inicialmente, foi realizada em 15 indivíduos saudáveis, sem anemia, de ambos os sexos, com idade entre 18 e 40 anos, sem distinção de raça ou grupo populacional. Para fazer a triagem dos pacientes com relação à presença ou não de anemia, foi realizado um questionário e um teste de microhematócrito - Ht, utilizando sangue de punção digital. Somente foram aceitos indivíduos com valores de $\mathrm{Ht}$ maior ou igual a $38 \%$ para homens e Ht maior ou igual a $35 \%$ para mulheres. Entre todos os pacientes tambémfoi realizada a pesquisa de hemoglobina $S$ pelo teste de solubilidade em microplaca, sendo recusados os pacientes com positividade nesse estágio da pesquisa. Para padronização da curva, o sangue utilizado precisou ser de indivíduos saudáveis para servir como controle, para saber como se apresenta uma curva de fragilidade osmótica normal; para tanto, foram realizadas as análises de 15 indivíduos diferentes demonstrando que a curva normal é comum para todos.

Estudo da Curva de Fragilidade Osmótica de amostras com alterações (segunda etapa): foram utilizadas amostras de sangue total de $4 \mathrm{~mL}$ colhidos com $\mathrm{K}_{2}$ - EDTA, após autorização prévia do paciente, 
junto ao Laboratório de Análises Clínicas da Santa Casa de Misericórdia de Araraquara, de 15 indivíduos de ambos os sexos, com idade entre 18 e 40 anos, sem distinção de raça ou grupo populacional e com hemograma apresentando microcitose, hipocromia, esferocitose, macrocitose, hemácia em alvo, hemácias falciformes, leucemia, leucocitose, desvio à esquerda/ granulações tóxicas. Foram realizadas análises do sangue de indivíduos com hemograma apresentando diferentes alterações hematológicas, para caracterizar como ficaria sua curva de fragilidade osmótica.

Aplicação da curva para hemogramas com alterações (estudo cego - terceira etapa): utilizamos as amostras de $4 \mathrm{~mL}$ de sangue total colhidos com $\mathrm{K}_{2}$-EDTA, após autorização prévia do paciente, junto ao Laboratório de Análises Clínicas da Santa Casa de Misericórdia de Araraquara, de 10 indivíduos que apresentaram hemograma alterado. Foi realizado um estudo cego para avaliar a eficácia do método previamente já padronizado, portanto, a aluna participante do trabalho não sabia quais eram as alterações hematológicas presentes em cada amostra. O conhecimento das alterações ocorreu somente no final do estudo.

Essas amostras de sangue total, que foram obtidas junto ao laboratório de análises clínicas citado neste item, foram colhidas dos pacientes que estavam fazendo exames laboratoriais de rotina no período da manhã, na época do estudo, por pessoal treinado do próprio laboratório, utilizando tubos, seringas e agulhas descartáveis. O estudo cego teve a finalidade de comprovar a eficácia do método e confirmar os resultados obtidos na segunda etapa, sem a aluna saber o que esperar do resultado.

\section{Apresentação e descrição das técnicas de} pesquisa (métodos)

Teste de Solubilidade - Screening de Hemoglobina S (LOUDERBACK et al., 1974).

- Técnica (adaptada para microplaca):

$\checkmark$ Identificou-se a microplaca com o número dos voluntários de forma crescente, horizontalmente da esquerda para a direita;

$\checkmark$ Os dois últimos poços foram dois controles positivos;

$\checkmark$ Dissolveu-se o ditionito de sódio $\left(\mathrm{NaSO}^{2}\right)$ em tampão difosfato $0,1 \mathrm{gr} / 10 \mathrm{~mL}$;

$\checkmark$ Foram dispensados $200 \mu \mathrm{L}$ desse tampão/ ditionito em cada poço da microplaca;

$\checkmark$ Pipetou-se $5 \mu \mathrm{L}$ do sangue a ser testado em cada poço homogeinizando;

$\checkmark$ Foram aguardados 10 minutos.

- Aleitura foi efetuada de duas formas:

$\checkmark$ Colocou-se a microplaca sobre um papel contendo uma linha negra:

- Teste Positivo: não foi possível ver a linha por causa da insolubilidade das hemácias (AS).

- Teste Negativo: foi possível ver a linha.

$\checkmark$ Pipetou-se com pipeta multicanal $5 \mu \mathrm{L}$ da reação da microplaca e sobre um papel de filtro:

- Teste Positivo: as hemácias insolúveis se depositaram formando um halo semelhante a um alvo (AS).

- Teste Negativo: difusão da hemólise pelo papel.

\section{Curva de Fragilidade Osmótica}

$\checkmark$ Numeraram-se 10 tubos de ensaio;

$\checkmark$ No tubo $\mathrm{n}^{\circ} 1$ colocou-se $0,4 \mathrm{~mL}$ de salina a $1 \%$; $0,5 \mathrm{~mL}$ no tubo ${ }^{\circ}{ }^{\circ} 2 ; 0,6 \mathrm{~mL}$ no tubo ${ }^{\circ}{ }^{\circ} 3$, e assim por diante (o último tubo deverá conter $1,3 \mathrm{~mL}$ );

$\checkmark$ No $1 .^{\circ}$ colocou-se $1,6 \mathrm{~mL}$ de água destilada, e assim por diante, em ordem decrescente (o $2 .^{\circ}$ tubo deverá ter 1,5 mL e o último, $0,7 \mathrm{~mL}$ );

$\checkmark$ Foram colocados em cada tubo $20 \mu \mathrm{L}$ de sangue (EDTA);

$\checkmark$ Os tubos foram homogeneizados suavemente, sem agitar;

$\checkmark$ Os tubos ficaram em repouso por 20 minutos em temperatura ambiente, e centrifugados em baixa rotação por 15 minutos;

$\checkmark$ Observou-se onde a hemólise se iniciou e onde ela foi total.

A leitura foi feita em espectrofotômetro em 540 nm, 
zerando o aparelho com água. O $1 .^{\circ}$ valor foi dividido por ele mesmo e multiplicado por 100 , correspondendo a $100 \%$; o $2 .^{\circ}$ pelo $1 .^{\circ}$ x 100 ; o $3 .^{\circ}$ pelo $1 .^{\circ}$ x 100 ; e assim por diante. A leitura foi feita em absorbância.

Esferocitose: curva à direita (aumento de hemólise)

Talassemia: curva à esquerda (diminuição de hemólise)

Observação: O presente teste foi realizado sem incubação, com incubação de 24 horas e com incubação de 48 horas em banho-maria a $37^{\circ} \mathrm{C}$.

\section{Resultados e discussão}

A padronização da Curva de Fragilidade Osmótica foi realizada na ausência e na presença de incubação em banho-maria a $37^{\circ} \mathrm{C}$ durante 24 ou 48 horas. No presente experimento, não se observaram diferenças entre as curvas nos diferentes períodos de incubação (Figura 1) e, a partir desses resultados, passamos a realizar as próximas etapas deste trabalho sem a fase de incubação.

$\mathrm{Na}$ literatura, existem relatos de que a incubação seria importante na caracterização de esferocitose hereditária ou outras formas de anemia onde exista a presença de esferócitos, pois a incubação dos eritrócitos previamente a sua realização sensibiliza o teste, devido à exposição das hemácias a um estresse metabólico que acentua o defeito dos eritrócitos, facilitando, desse modo, a interpretação da curva (LEE et al., 1998). Infelizmente, durante o período de realização deste trabalho, nenhuma amostra com quantidades consideráveis de esferócitos entrou para os grupos de estudo para podermos confirmar esses dados.

A resistência dos eritrócitos depende da relação entre a superfície e o volume da hemácia. No presente experimento avaliamos como as diferentes alterações hematológicas se portaram frente a diferentes concentrações de $\mathrm{NaCl}$.

Como demonstrado na Figura 2, a curva se mostrou voltada para a esquerda, ou seja, as hemácias demonstraram fragilidade diminuída quando microcíticas e hipocrômicas, alterações encontradas tanto na anemia ferropriva como nas talassemias. Esses resultados corroboram relatos da literatura (WALLACH, 2003). Devido à menor concentração de hemoglobina dentro das hemácias (hipocromia), um maior volume de água pode entrar antes que estas arrebentem.

Não encontramos relatos na literatura que indicassem alteração da Curva de Fragilidade Osmótica na presença de eliptócitos ou ovalócitos. Essa ausência de efeito também foi observada no presente estudo (Figura 3).

Em estados infecciosos, vários trabalhos demonstram o envolvimento de espécies reativas de oxigênio -Eros, aumento de peroxidação lipídica e diminuição da atividade de enzimas antioxidantes naturais do organismo (DARLEY-USMAR e HALLIWELL, 1996). Consequentemente, a membrana eritrocitária se apresenta, nesses casos, mais frágil. Wallach (2003), em estudo anterior, demonstrou que a Curva de Fragilidade Osmótica se apresentou aumentada para hemácias de pacientes com infecção (hemograma apresentando leucocitose ou leucopenia, seguido ou não por desvio à esquerda e presença de alterações tóxicodegenerativas, como granulações tóxicas).

No presente trabalho não observamos alterações na curva de pacientes com quadros infecciosos. A possível explicação para o ocorrido é que, talvez, os casos analisados não fossem de gravidade considerável a ponto de gerar Eros em concentrações suficientes para causar peroxidação lipídica e lesão de membrana (Figura 4).

A Curva de Fragilidade Osmótica avalia a capacidade dos glóbulos vermelhos de incorporar água em seu interior, sem que ocorra a lise da célula. Consequentemente, quanto maior o volume do glóbulo maior a quantidade de água intracelular e, com isso, uma menor fragilidade osmótica. Portanto, hemácias macrocíticas e em alvo têm uma maior capacidade de permanecer íntegras em soluções hipertônicas do que hemácias normais (Figura 5), e foi justamente o que observamos no presente trabalho. 
$\mathrm{Na}$ anemia falcimorme e também no traço falciforme, devido à mutação na cadeia $\beta$ de globina, encontramos $\mathrm{HbS}$ que pode exibir comportamento oxigenado, considerado normal ou desoxigenado, sofrendo polimerização, formando uma rede gelatinosa de polímeros fibrosos. Esses polímeros alteram a característica do eritrócito, que passa a ter sua membrana mais rígida; é também observado aumento da viscosidade sanguínea, desidratação celular devido à perda de potássio e deformação do eritrócito característico dessa anemia hemolítica (KELLEY,
1999). Essas células perdem a flexibilidade e não têm a capacidade de atravessarem pequenos capilares (BRASIL, 2006; ZAGO et al., 2001). Devido a essa alteração de membrana com maior rigidez, os eritrócitos apresentam diminuição da curva de fragilidade osmótica (Figura 6).

No experimento de aplicação da Curva de Fragilidade Osmótica, para todos os pacientes estudados observamos para cada patologia o mesmo padrão da curva quando comparado às análises já realizadas (dados não mostrados).

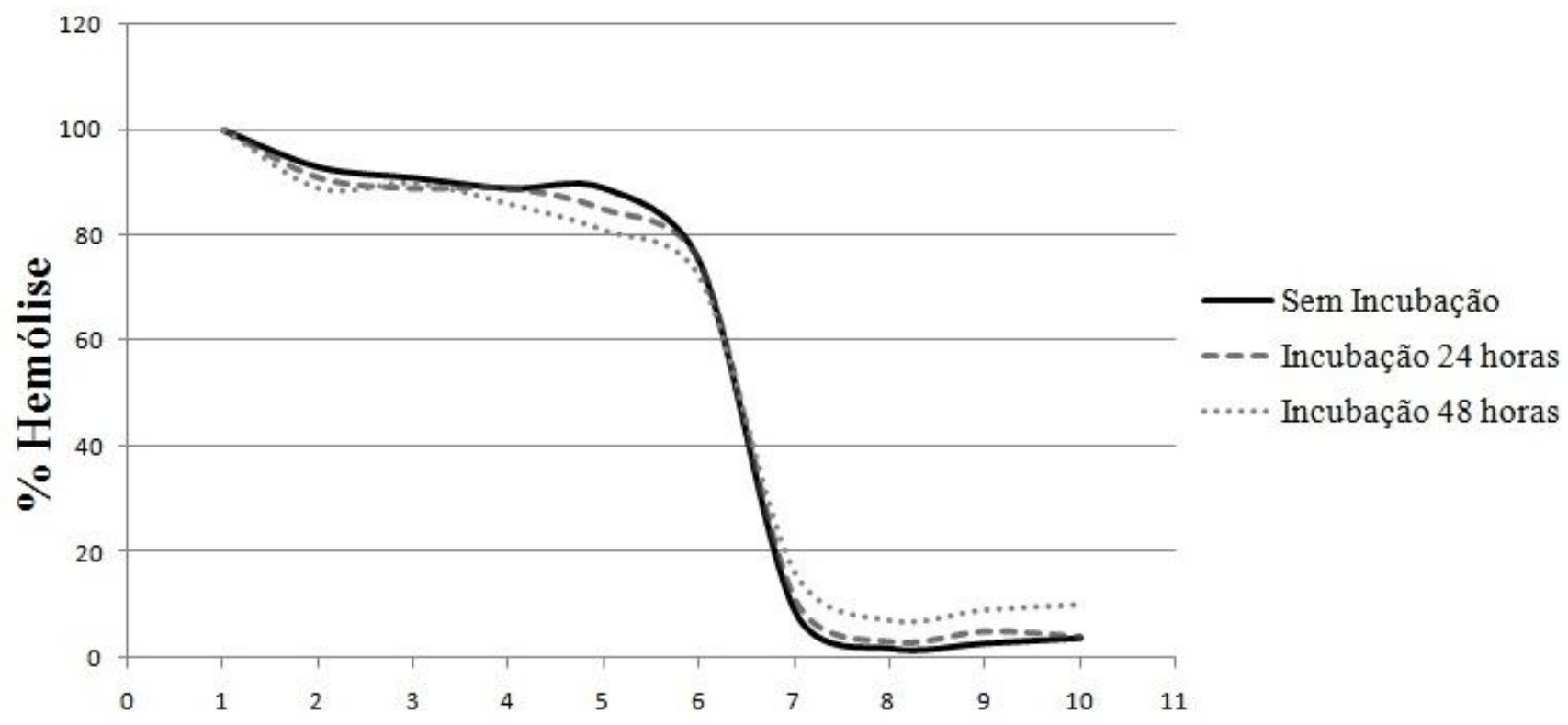

Tubos de Reação

Figura 1 - Padronização da Curva de Fragilidade Osmótica.

Fonte: Dados de pesquisa. 
Padronização e aplicação da Curva de Fragilidade Osmótica...

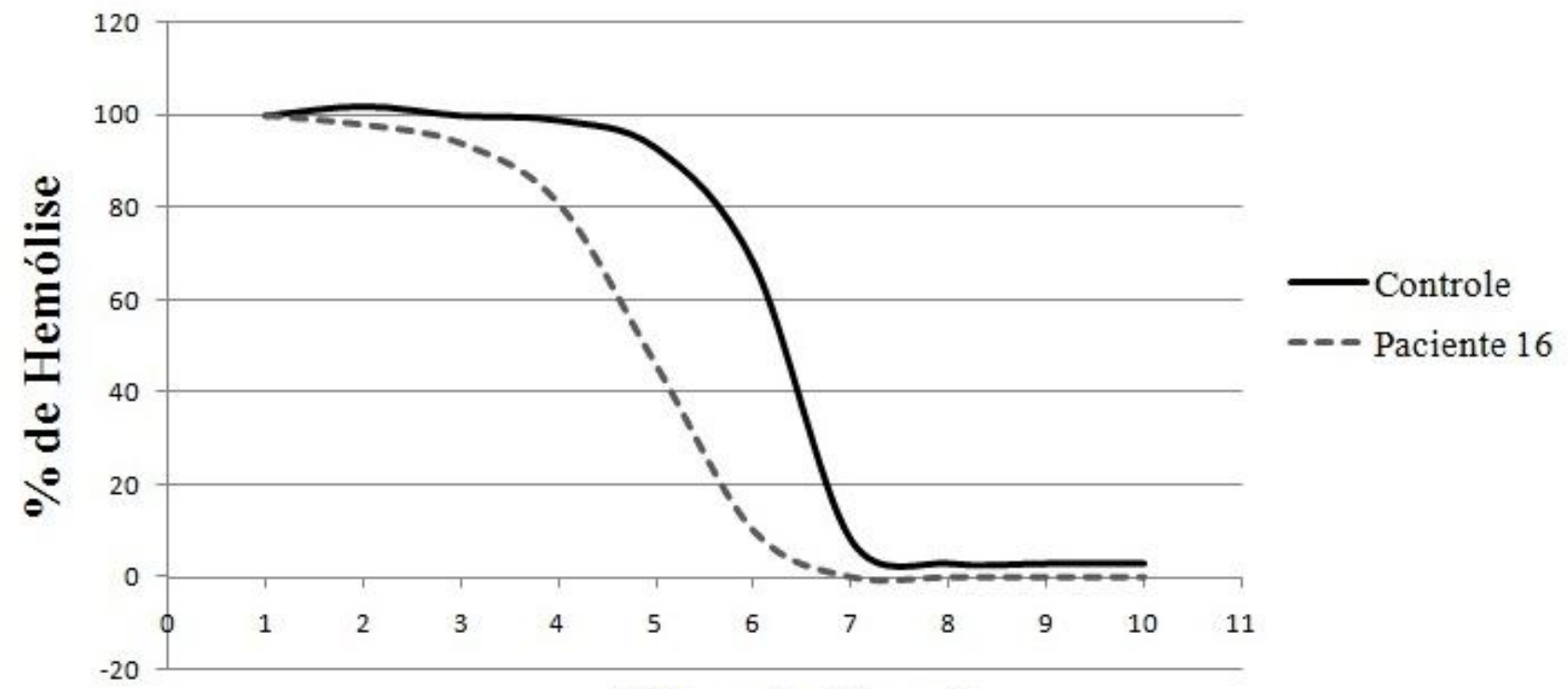

Tubos de Reação

Figura 2-Beta Talassemia Menor.

Fonte: Dados de pesquisa.

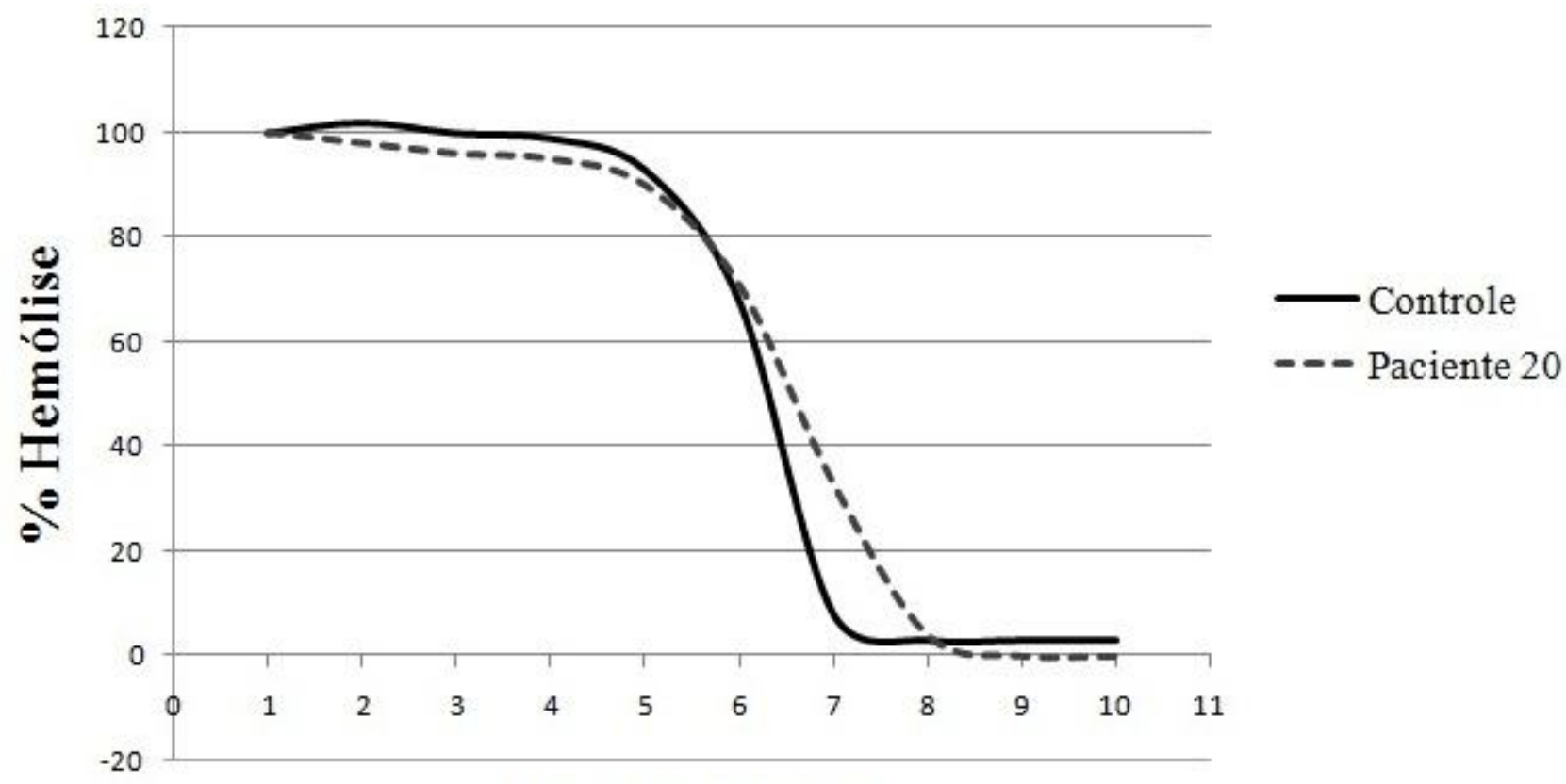

Tubos de Reação

Figura 3 - Moderada Anisocitose com Microcitose; Moderada Hipocromia; Discreta Poiquilocitose com Eliptócitos.

Fonte: Dados de pesquisa. 


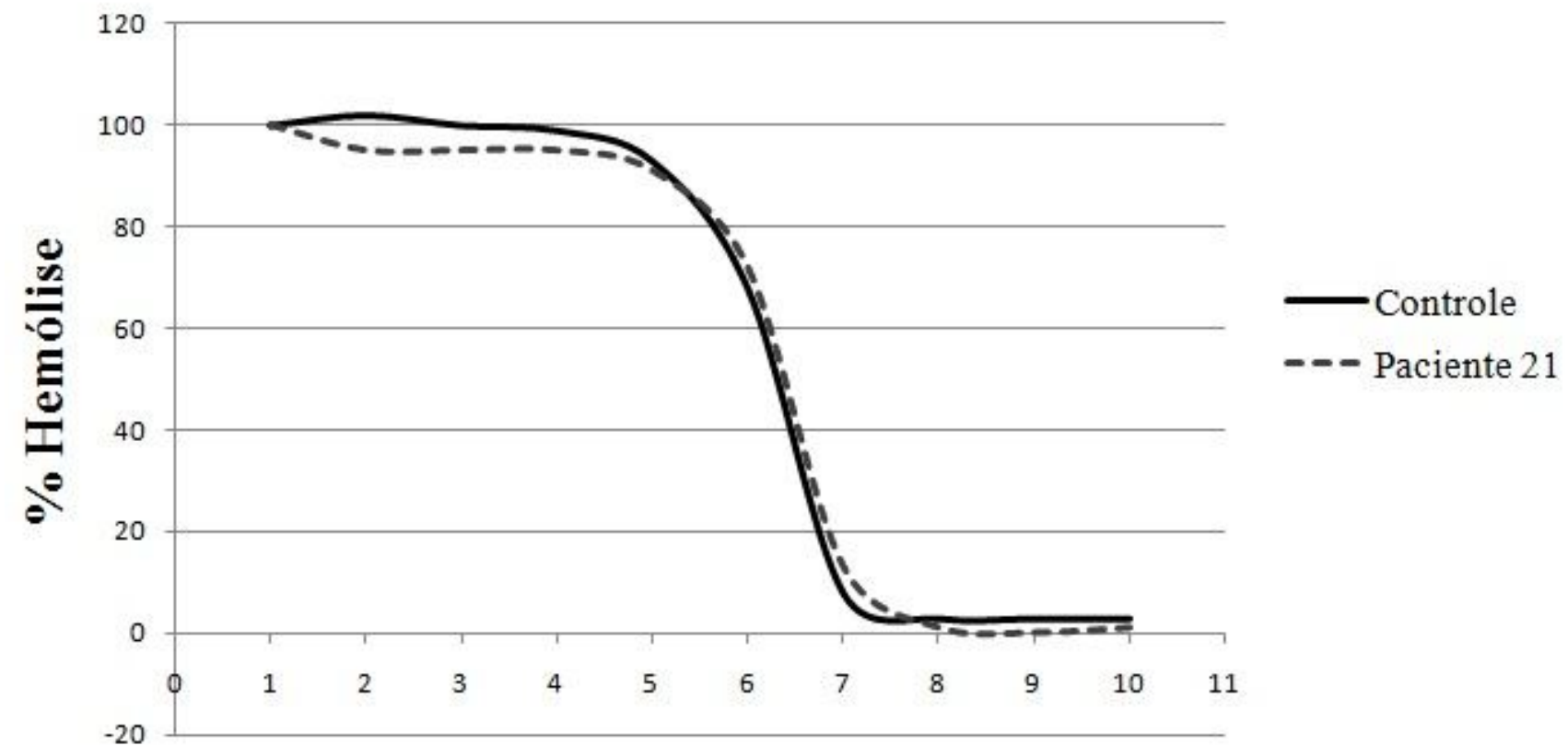

\section{Tubos de Reação}

Figura 4 - Moderada Granulações Tóxicas.

Fonte: Dados de pesquisa.

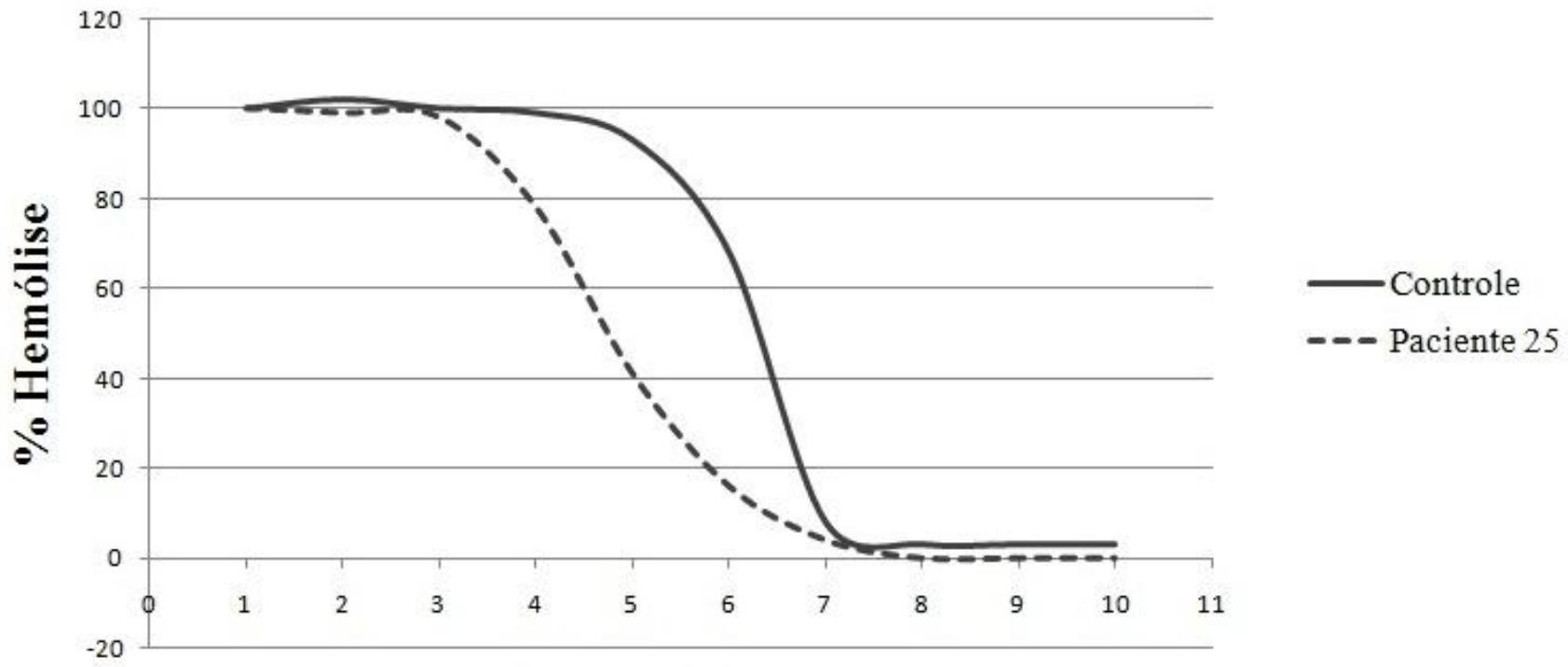

\section{Tubos de Reação}

Figura 5 - Discreta Poiquilocitose com Esquisócitos e Hemácias em Alvo; Moderada Anisocitose com Microcitose e Hipocromia.

Fonte: Dados de pesquisa. 
Padronização e aplicação da Curva de Fragilidade Osmótica...

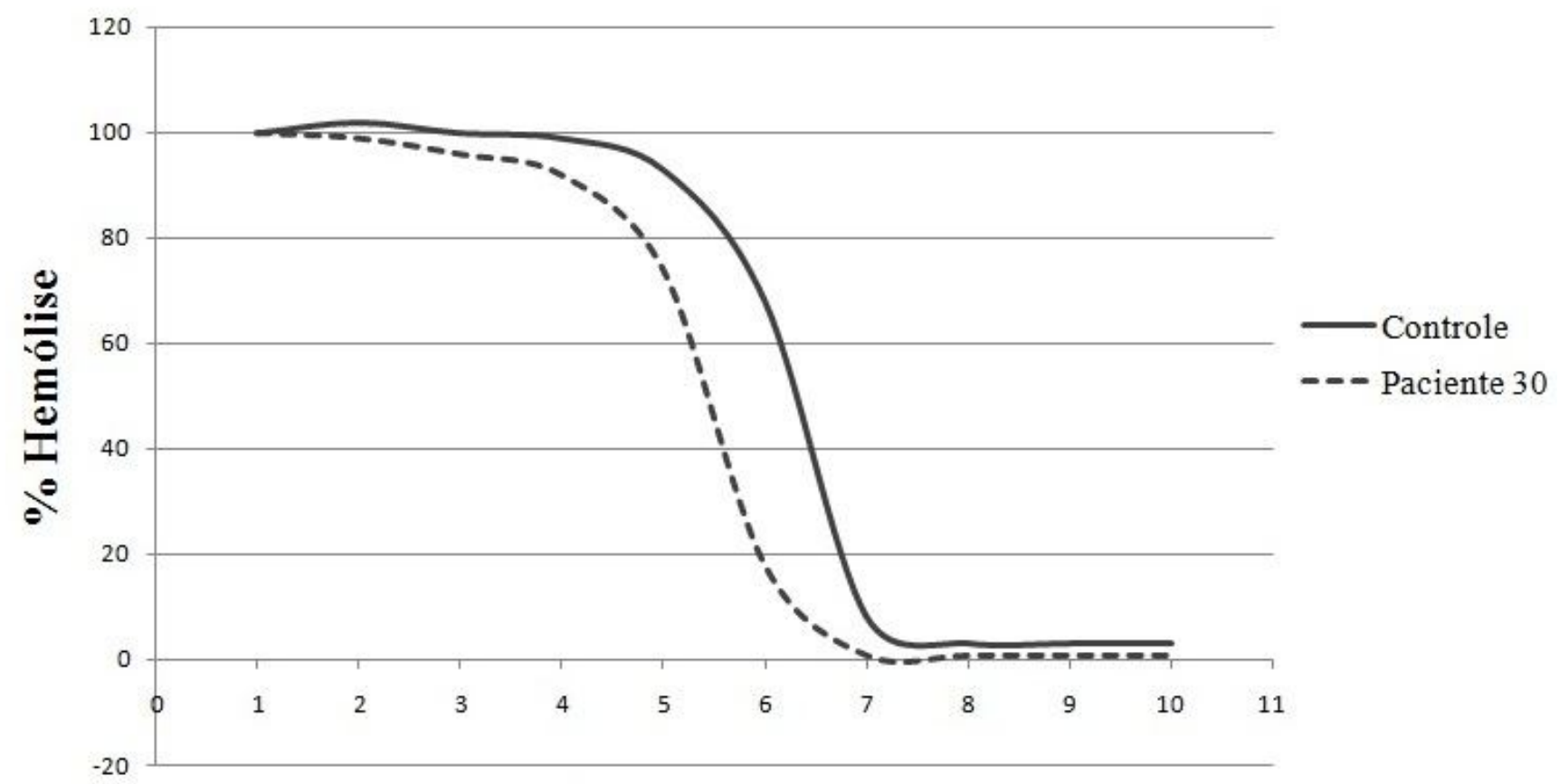

Tubos de Reação

Figura 6 - Traço Falciforme.

Fonte: Dados de pesquisa.

\section{Conclusão}

O presente trabalho demonstrou que não existe a necessidade de incubação para a execução da Curva de Fragilidade Osmótica, pois as curvas padronizadas nos diferentes tipos de incubação se apresentaram semelhantes.

A metodologia é útil quando associada ao hemograma para auxílio na caracterização de anemias megaloblásticas, anemia ferropriva, presença de $\mathrm{HbS}$, talassemias e hemácias em alvo.

A curva não se demonstrou alterada nos casos da presença de eliptócitos, portanto, estando essa alteração presente, associada às outras anemias, sabese que não será a responsável pela modificação da curva.

Não se demonstraram alterações na curva de pacientes com infecção leve/moderada (granulações tóxicas), estando provavelmente a alteração relacionada à gravidade do processo infeccioso.

\section{REFERÊNCIAS}

BRASIL, Ministério da Saúde. Manual de Condutas Básicas na Doença Falciforme. Brasília: MS, 2006.

Ceaclin. Fragilidade Osmótica das Hemácias. Disponível em: <http://www.ceaclin.com.br/exames/ fragilidade_osmotica.shtml $>$ Acesso em: 20. out. 2012.

DARLEY-USMAR, V.; HALLIWELL, B. Blood Radicals: Reactive Nitrogen Species, reactive Oxygen Species. Transition Metal Ions, and the Vascular System. Pharmaceut. Res. 13:649-662, 1996. 
FISCHBACH, F.T.; DUNNING, M.B. A Manual of Laboratory and Diagnostic Tests. Editora

Lippincott Wiliams \& Wilkins, 2008. p.117.

KELLEY, W.N. Tratado de Medicina Interna. Rio de Janeiro: Ed. Guanabara Koogan S.A., 1999.

\section{KHURANA, I. Textbook Of Medical}

Physiology. Editora Elsevier India, 2006.

LEE, G. et al . Wintrobe: Hematologia Clínica. 4. ed. v. I. São Paulo: Ed. Manole LTDA, 1998.

\section{PARDINI, H. Atualização do Manual de Exames} 2009. Disponível em: http:// www.hermespardini.com.br/atual_manual/ manual.php. Acesso em: 20.out.2012 .

POYART, C.; WAJCMAN, H. Hemolytic due to homoglobinopathies. Mol. Aspects Med., v.17, p.129-142, 1996.
SCHWARTZ, E. Abnormal globin synthesis in thalassemic red cells. Semin. Hematol., v.11, p.549$567,1974$.

VERRASTRO, T. et al. Hematologia e

Hemoterapia: Fundamentos de Morfologia, Fisiologia, Patologia e Clínica. São Paulo: Atheneu, 2002.

WALLACH, Jacques M.D. Interpretação de Exames Laboratoriais. 7. ed. Rio de janeiro: Medsi e Ed. Guanabara Koogan S.A, 2003.

WEATHERALL, D.J. The thalassaemias. B.M.J., v. 314, p.1675-1678, 1997.

WILIAMS \& WILKINS, L. Nursing, The Series For Clinical Excellence: Decifering Diagnostic Tests. Philadelphia: Editora Lippincott Wiliams \& Wilkins, 2007. p.04.

ZAGO, M. A. et al. Hematologia: Fundamentos e Prática. São Paulo: Atheneu, 2001. 